Connotas. Revista de crítica y teoría literarias 
CONNOTAS. REVISTA DE CRÍTICA Y TEORÍA LITERARIAS. Enero - diciembre 2013, es una publicación anual editada por la Universidad de Sonora, a través de la División de Humanidades y Bellas Artes, en el Departamento de Letras y Lingüística. Blvd. Luis Encinas y Blvd. Rosales s/n, Col. Centro, C.P. 83000, Hermosillo Sonora; Tel. (662) 2592 136, (662) 2592 157, <www.uson.mx>, <http://www.connotas.uson.mx, connotas@capomo.uson.mx>. Editor responsable: Rosario Fortino Corral Rodríguez. Reservas de Derechos al Uso Exclusivo núm. 04-2006-020714184900-102. ISSN: 18706630; ambos otorgados por el Instituto Nacional del Derecho de Autor. Licitud de Título núm. 13434 y de Contenido núm. 11007, otorgados por la Comisión Calificadora de Publicaciones y Revistas Ilustradas de la Secretaría de Gobernación. Este libro se publicó con el apoyo del Programa Integral de Fortalecimiento Institucional C/PIFI 2013-12934

Se autoriza la reproducción total o parcial de los contenidos de la presente publicación, siempre y cuando se acredite adecuadamente el origen de los mismos.

Datos de contacto para la publicación: División de Humanidades y Bellas Artes, Departamento de Letras y Lingüística; Apartado Postal 793, Col. Centro, C.P. 83000, Hermosillo, Sonora, México. Tels.: (662) 259-21-87, Tel-fax 212-55-29. Correo electrónico: connotas@capomo.uson.mx Página web: http://www.connotas.uson.mx 


\section{Connotas. Revista de crítica y teoría literarias}

Núm. 13, año 2013

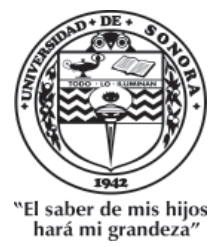


UNIVERSIDAD DE SONORA

RECTOR

Heriberto Grijalva Monteverde

VICERRECTORA

Arminda Guadalupe García de León Peñúñuri

Secretario General Académico

Enrique Fernando Velázquez Contreras

División de Humanidades y Bellas Artes

María Rita Plancarte Martínez

Departamento de Letras y LingÜística

Ana Bertha de la Vara Estrada

César Avilés Icedo

Rosa María Burrola Encinas

Fortino Corral Rodríguez

Leticia Martínez Figueroa

Jesús Abad Navarro Gálvez

Gabriel Osuna Osuna

María Rita Plancarte Martínez

DiRECTOR

Fortino Corral Rodríguez

Giuseppe Bellini

Consejo InTERnacional

Universidad de Milán

Carlos Pacheco

Luis Beltrán Almería

Universidad Simón Bolivar

Universidad de Zaragoza

Rafael Olea Franco

Helena Beristáin

El Colegio de México

Joan Oleza Simó

Universidad Nacional Autónoma de México

Universidad de Valencia

Raúl Bueno-Chávez

Dartmouth College

Julio Ortega

Evodio Escalante

Brown University

Luz Aurora Pimentel

Universidad Autónoma Metropolitana

Universidad Nacional Autónoma de México

Beatriz González-Stephan

Susana Reisz

Rice University

Aníbal González

The City University of New York.

José Carlos Rovira

Universidad de Alicante

Yale University

Aurelio González Pérez

Charles Tatum

El Colegio de México

Yvette Jiménez de Báez

The University of Arizona

Jorge Urrutia

El Colegio de México

Universidad Carlos III de Madrid

Nelson Osorio Tejeda

Universidad de Santiago de Chile

Emil Volek

Arizona State University 


\section{Índice}

\section{Artículos}

Una hermenéutica analógica para la literatura

Mauricio Beuchot Puente

La obra de Jorge Luis Borges durante la década de 1930: estudio de algunos elementos para la conformación de su poética en Discusión (1932)

Daniel Zavala Medina

Metáforas de la locura y la muerte en "Río subterráneo" de Inés Arredondo

Gabriel Osuna Osuna

La alteridad como vector de la construcción del yo: La muerte me da de Cristina Rivera Garza y El Gran Vidrio de Mario Bellatin Véronique Pitois Pallares

Uno soñaba que era rey de Enrique Serna: un espacio de contradicción Claudia Gidi

Una angustia compartida. Análisis de la voz narrativa en Mi hermano Carlos de Jorge López Páez

Jorge Antonio Muñoz Figueroa

De Los perros románticos y otros poemas de Roberto Bolaño Marina Martínez Andrade 
Las novelas del Crack, multiplicidad y superposición de mundos Ramón Alvarado Ruiz

La construcción del “otro" en la Relación de la jornada de Cíbola de Pedro Castañeda de Nájera

Guillermo Martínez Sotelo

Destino e historia en Margarita, está linda la mar de Sergio Ramírez

María Rita Plancarte Martínez

\section{Notas}

Identidad negada y mundo al revés en Santa María del Circo de David Toscana

César Avilés Icedo y María Elena González Borgaro 203

"El buen ejemplo" de Vicente Riva Palacio: la historia de un cuento

Marco Antonio Chavarín González

Organización descriptiva en Catarina de San Juan, princesa de la India y visionaria de Puebla

Silvia Guadalupe Alarcón Sánchez

Genealogías en Todo aqui es polvo de Esther Seligson. Lectura a partir de los epígrafes

Luz Elena Zamudio Rodríguez

\section{Reseñas}

Martha Elena Munguía Zatarain. La risa en la literatura mexicana (apuntes de poética)

Silvia Alicia Manzanilla Sosa 
Véronique Pitois-Pallares. El arte del fragmento: El Gran Vidrio de Mario Bellatin

Julio César Zárate Ramírez 255

Nicolás Kanellos. Hispanic Immigrant Literature: El sueño del retorno Josué Gutiérrez González

Dante Salgado. Brevísima relación de la idea de amor en Occidente Diana Vanessa Geraldo Camacho 271

Mara L. García. Paco Yunque: una mirada crítica Juan Paredes Carbonell 279

Abstracts 283

Résumés

Normas editoriales 



\title{
Destino e historia en Margarita, está linda la mar de Sergio Ramírez
}

\author{
María Rita Plancarte Martínez
}

Resumen:

Margarita, está linda la mar (1998), del nicaragüense Sergio Ramírez, se nos ofrece como un universo ficticio de representaciones en el que se entretejen, en diferentes tiempos, los hechos y personajes históricos con hechos y personajes de la vida cotidiana, de manera que la historia pierde su condición estática para convertirse en la dinámica de la vida misma. La historia se conceptualiza como un proceso azaroso en el que la voluntad humana se enreda y no logra alcanzar a dibujarse metas distintas a las del azar. Sólo una voluntad heroica puede intentar, apenas, contravenir el destino y modificar el devenir de la historia.

Palabras clave:

Novela histórica, Modernismo, Rubén Darío, heterogeneidad narrativa, literatura nicaragüense.

Margarita, está linda la mar (1998), del nicaragüense Sergio Ramírez, se nos ofrece como un universo ficticio de representaciones en el que se entretejen, en diferentes tiempos, los hechos y personajes históricos con hechos y personajes de la vida cotidiana, de manera que la historia pierde su condición estática para convertirse en la diná-

\footnotetext{
* Universidad de Sonora.
} 
mica de la vida misma. Dinámica en la cual todas las acciones, aun las más nimias, adquieren un valor capaz de determinar el curso de los acontecimientos.

En los últimos años muchos estudiosos se han dado a la tarea de definir y explicar las particularidades de la novela histórica, ya que ha sido un género pródigamente transitado por los novelistas contemporáneos, no sólo en Hispanoamérica. En este caso, la construcción novelesca, su dimensión metaficcional y las relaciones de intertextualidad que entabla con otras obras hispanoamericanas, amén del evidente contenido de la trama en la que se implican y ficcionalizan sucesos históricos reales llevan a ubicarla como novela histórica. De hecho, el propio Seymour Menton, quien se ocupara en discernir las caraterísticas de la llamada "Nueva novela histórica hispanoamericana" indica, en 2004, que la obra de Ramírez es: "La mejor de las novelas históricas nicaragüenses de la la última década y la única que podría calificarse de nueva". Partiendo, entonces, de que la obra cumple con las características propias del mencionado género, me propongo hacer un análisis textual de la tematización de la historia y la conceptualización que le subyace en Margarita, está linda la mar.

En la trama de la novela convergen dos momentos históricos diferentes y las series de sucesos que les corresponden a cada uno: por un lado, se narran pasajes de los últimos años de un Rubén Darío decadente de principios del siglo XX y, por otro, el complot para atentar contra la vida de Anastasio Somoza en 1956, así como lo sucedido el día del atentado. Las acciones de la novela se ubican en León, Nicaragua, en el mismo espacio sólo que en dos momentos distintos.

La obra está compuesta en dos partes, divididas entre sí por un "Intermezzo tropical". Cada parte está constituida por capítulos cuyos títulos están tomados de la obra poética de Rubén Darío. Dichos títulos indican una clara intención autoral de hacer viva y presente la voz de Darío en el universo novelesco.

En la obra, Ramírez incorpora diversos registros o formas. De modo que podemos encontrar en la novela diálogos dramáticos, discurso legal, epístola, investigación histórica o reportaje. Esta heterogeneidad formal pudiera indicar el interés del autor por construir un 
universo ficcional dinámico y abarcador, capaz de contener múltiples formas en convivencia, cuya funcionalidad textual pudiera ser la de presentar las diversas formas que asumen los discursos que dan cuenta de los sucesos históricos. También pudieran servir como contrapunto o complemento a la perspectiva narratorial que preside la novela.

Lo anterior lleva a pensar que en la obra se puede reconocer la presencia del autor implícito - de acuerdo a la categoría propuesta de Seymour Chatman- que sería el eje de selección y organización de las formas de representación del mundo narrado y quien, en última instancia, orienta la recepción de la obra al hacer presente de manera insistente, por ejemplo, la palabra poética de Rubén Darío.

Los títulos de los capítulos siempre tienden a relacionar el mundo poético del nicargüense con el universo ficcional de la novela, creando así un extraño diálogo entre la narración y la poesía. Digo extraño porque en el texto no se resuelve del todo, pero adquiere un valor similar al de telón de fondo. Tal diálogo pudiera entenderse, también, desde un punto de vista que diera a la voz poética la capacidad de trascender el tiempo para ser una voz con función de presagio o de profecía. El autor implícito actualiza la voz modernista y la trae al presente de la narración con esta última intención.

Este autor implícito construye una voz narrativa principal cuya tonalidad y funcionalidad corresponde a las formas de los narradores decimonónicos. Se trata de un narrador omnisciente, que transgrede las formas de la omnisciencia pues se reconoce a sí mismo en el texto aunque nunca asume una posición específica ni actorial en el relato. Esto es, en términos de Gennete, su ubicación con respecto del mundo narrado corresponde a un narrador heterodiegético, pero trasciende la mera función vocal para identificarse como una conciencia con limitaciones cognitivas y sensoriales, como se puede ver en el siguiente pasaje:

Los desacuerdos de este diálogo no se explican sin un antecedente inmediato: Rigoberto había hecho una estación en la casa de Rosaura en el barrio de San Juan, no prevista para mí, y por eso hasta ahora puedo darles cuenta. Ya dije que no era un día fácil. (224) 
En la novela también se puede reconocer una voz narrativa secundaria, la de Rigoberto -el personaje que atentará contra la vida de Anastasio Somoza- que desde el discurso de la investigación histórica reconstruye pasajes de la vida de Rubén Darío. El paso de una vOz a otra es casi imperceptible y sólo se reconoce por medio de las situaciones contextuales de diálogo en el que generalmente tiene lugar:

La contera de sombrilla plegada apunta a Eulalia en medio de los ojos, como un arma mortal, allí donde se encuentran en un nudo oscuro las cejas espesas. Y los concurrentes quedan congelados en sus gestos como bajo un resplandor de magnesio. -¿Quién es esa puta? -dice al fin, colérica.

-¿Y qué hizo entonces Rubén? -pregunta Norberto. (30)

La voz narrativa entonces se ubica en dos lugares de enunciación diferentes pero complementarios. Por un lado, está el narrador omnisciente en tercera persona y por otro, está la voz de Rigoberto, personaje que funciona como un narrador delegado. De manera que las acciones de Rigoberto son el objeto de enunciación de la vOZ principal y las acciones de Rubén Darío son el objeto de enunciación de la voz secundaria o delegada.

En la primera y segunda parte de la novela se puede distinguir el paso constante y de una voz a otra, lo que no sucede en el "Intermezzo tropical” que está conformado por dos secciones: la primera corresponde a la reconstrucción que hacen los contertulios de la "mesa maldita" del curriculum de Anastasio Somoza; este relato pormenorizado y comentado por los contertulios no se puede adjudicar al narrador principal sino a una suerte de narrador investigador cuya visión de la historia no es, precisamente, la de la historia oficial. Este discurso representa una estilización del lenguaje de la historia, que sin ser retomado en el texto como tal, aparece refractado en esa estilización.

La visión y valoración de los hechos históricos se contrapone al conjunto de imágenes, conceptos y valores con los que se ha construido el discurso oficial de la historia. Así, la historia de Nicaragua se presenta como una historia de bandidaje, referida en el texto con 
un estilo que la despoja del carácter heroico que le ha conferido la historia escrita por los vencedores:

\section{3.}

Su tíopolitico, Juan Bautista Sacasa, asume la presidencia (1933-1937) tras ganarla en elecciones libres (también supervigiladas por los marines). Las tropas de ocupación salen de Nicaragua. Asume el cargo de Jefedirector de la recién formada Guardia Nacional, de una vez con el grado de General de División que merece por la herida en el asalto del cuartel de Masatepe. Incorpora a Justo Pastor Gonzaga con el grado de Coronel, y lo nombra Tesorero General. También incorpora a Melisandro Maravilla con el mismo grado, y lo nombra Jefe de Abastos. Sandino firma la paz. con Sacasa. (169)

Esta contraposición se puede entender como estilización en tanto se monta sobre los mismos acontecimientos que reconoce la historia oficial pero se modifica el tono y el punto de vista, para llegar a cuestionar la credibilidad del discurso oficial. Pero no es sólo el cuestionamiento de esta forma, hay una búsqueda explícita de restituir a la historia el nivel vivencial de los actores, sujetos y objetos del proceso histórico:

(iVean qué favor!, el orfebre Segismundo golpea la mesa con la palma de la mano. ¡De ese pacto nació la dinastía! Si Dillinger muere, ya está listo el hijo. Y le dice Erwin: eso será quién sabe cuándo, porque el 21, aqui al otro lado, en el Teatro González, el viejo Tacho quedará ungido para seis años más, y asi per secula secolurum. Hasta que alguien que se eche los huevos al hombro, dice el orfebre Segismundo...) (175)

La segunda sección del "Intermezzo tropical" la constituye la carta que Rigoberto envía a su madre donde le explica las razones por las cuáles atentará contra la vida de Somoza. El discurso patriótico de Rigoberto constituye la expresión de su propia voluntad y los riesgos que asume, en el sentido vivencial apuntado arriba.

La narración principal, en donde se alternan las voces del narrador principal y el secundario, está contagiada de un tono modernista que se reconoce en los recursos estilísticos propios de tal tendencia. 
El lenguaje lleno de metáforas, el tono y la configuración de las descripciones, entre otros aspectos, corresponden a la reelaboración de las formas propias del modernismo. La presencia insistente de los versos de Rubén Darío se puede reconocer incluso en el cuerpo de la novela. "Un gran vuelo de cuervos mancha el azul celeste" o "Quirón lo oye todo, para eso tiene el oído sideral de los centauros" son ejemplos de versos introducidos en la narración; además se pueden reconocer este estilo modernista en un buen número de expresiones similares a la siguiente: "Los cipreses del jardín en sombras, por el que deambula una pareja de pavorreales, se estremecen con los invisibles soplos de brisa que presagian lluvia" (61). También, en la novela la cantina se llama "La fuente castalia"; la imprenta "Cara lutecia"; Quirón lleva el nombre de un personaje poético de Prosas profanas, lo mismo que algunas de las mujeres personajes como la Mora Zela, o la Rosa Niña.

El modernismo no está sólo en las alusiones darianas, sino también en la configuración de un narrador que interpela a los lectores al mismo tiempo que los guía por los meandros del mundo narrado: "Ahora, mejor vengan conmigo al Hospital San Vicente" (347), "El Capitán Prío no podía apreciarlo tan de cerca, pero voy en su auxilio" (57).

Según Isolda Rodríguez Rosales el modernismo en la obra de Sergio Ramírez es tal que está construida sobre el esperpento, técnica creada por Valle Inclán, que esta autora explica así:

En Luces de Bohemia (donde Rubén es uno de los personajes) Max Valle expresa: "Mi estética actual es transformar con matemática de espejo cóncavo las normas clásicas... Deformemos la expresión en el mismo espejo en que nos deforma las caras y toda la vida miserable de España” (escena XII). Estas palabras revelan la peculiaridad del esperpento como modo de expresión, una estética sistemáticamente deformada, que quiere reflejar la vida miserable de España. (63)

Creo que, si bien es cierto que la presencia del modernismo en la novela es evidente, no lo es tanto la presencia del esperpento en 
sentido estricto. Los personajes son parodias de sí mismos -desde Rubén Darío, hasta Anastasio Somoza, pasando por Rigoberto López Pérez- de una manera más moderna que la propuesta por el esperpento. Dice la misma autora "El esperpento consiste en la preocupación y propósito de expresar los problemas del país, en el caso de Ramírez Mercado, la de Nicaragua"(63). Me parece que la propuesta del autor no es expresar los problemas de su país, sino que elabora un universo novelesco que, entre otras cosas, pone en evidencia las múltiples formas en las que se construye la historia. En la medida en que la trama se elabora a partir de sucesos reales remite a un momento específico de la historia nicargüense, aunque no implica, necesariamente, una intención de expresar los problemas de ese país.

En otras palabras, me parece que al construir sus personajes Ramírez hiperboliza y ridiculiza las condiciones que determinan al ser humano y prescriben su inserción en la historia, pero no estoy tan segura de que su intención central sea presentar una realidad deformada sino más bien pienso que trata de organizar un sistema de representaciones capaz de dar cuenta de la trascendencia de las acciones individuales en la historia, de ahí la multiplicidad de registros en la novela.

La inclusión de los diversos registros mencionados configura un narrador no autoritario, por lo que se puede concluir que es más bien un narrador contemporáneo que juega a parecer decimonónico: "Y si quieren escuchar qué le dice, acérquense conmigo a ese oído, y también usted aguce el suyo en su atalaya, Capitán, y ustedes, las hermanas remendonas, despierten, es tiempo ya de poner atención y alistar los hilos de su labor" (229).

El narrador principal constituye en narratarios, tanto a los personajes mismos - al Capitán Prío, por ejemplo- como a los lectores, pues los interpela constantemente de manera explícita. Los narratarios del narrador secundario son los contertulios de la "mesa maldita" a quienes les lee sus avances de investigación y quienes pueden debatir con el autor las limitaciones de su conocimiento:

Quiso besarla, pero sólo alcanzó a rozarle la mejilla porque ella quitó el rostro con gesto de asco, reprendiéndolo: apenas 
amanece, ya estás oliendo a licor. ¿No te da vergüenza? -No preste oídos a invenciones, maestro -le dice Erwin al orfebre Segismundo-. Rosario Murillo ni siquiera había regresado a Nicaragua. Llegó en otro barco, una semana más tarde, también de Panamá. Ese barco era el Bernardo O’ Higgins, de bandera chilena. (31)

Los personajes constituidos en narratarios de la voz secundaria establecen un debate con esta $\mathrm{vOz}$, la interpelan, debaten con sus puntos de vista y, lo más interesante es que, desde la perspectiva de estos personajes, los hechos históricos tienen un correlato con la realidad que ellos viven, de manera que la historia pierde su calidad de suceso concluido y cerrado para convertirse en una dimensión actuante en la vida cotidiana:

Ahora es Salvadorita la que corre hacia Rubén y se abraza a sus piernas. Él se inclina para besarla, la flor de trapo apretada en su mano.

-No mates nunca a tu ruiseñor -le dice al oído.

-El ruiseñor que se llena el buche de manera descarada -dice el orfebre Segismundo. (140)

Como decía, en Margarita, está linda la mar, Sergio Ramírez logra entramar dos momentos distantes en el tiempo: los últimos años de Rubén Darío y el atentado que culmina con la muerte de Anastasio Somoza en 1956.

Las acciones de la novela se ubican en diferentes tiempos que se combinan en un complicado juego temporal. El aquí y el ahora de la narración corresponde a un día completo, el 21 de septiembre de 1956, día del atentado a Somoza:

Rigoberto, que a esta hora no sabe nada de la prisión de Cordelio. Ya se ha vestido también para la fiesta; ya puso la carta para su madre en el tramo superior del ropero, junto con el cartapacio donde guarda su cuaderno de apuntes. Busquen ese cuaderno, lean rápido, que mañana ya no estará allí. Sólo para empezar, Rubén va a ser sepultado hoy 13 de febrero de 
1916 en la catedral al pie de la estatua de San Pablo, y habrá, además, una petición de mano en pleno funeral... (314-315)

Desde este punto de partida temporal la narración retrocede por medio de analepsis y concluye en una prolepsis en la forma de un reportaje que da cuenta del epílogo del atentado.

En un complicado juego de analepsis, el narrador reconstruye los días previos al atentado, así como los antecedentes de la conspiración, el 6, 8 y 19 de septiembre: “-Para llegar hasta Somoza, pasando por el robo del cerebro, faltan muchos avatares -dice Rigoberto-. Ojalá pueda terminar de leerles todo eso antes de que llegue el 21" (203).

Estas rupturas temporales dan lugar a la presentación de los sucesos antecedentes que van a culminar con el atentado. Así, por medio del narrador principal nos enteramos de los trabajos que pasan los conspiradores para financiar su empresa. Se dibuja así una historia que carece de dimensiones heroicas pues lejos de conseguir el dinero por formas más o menos normales, colectas o algo así, el financiamiento se logra mediante la satisfacción del apetito sexual de una mujer adinerada.

Y a la mañana siguiente, regresó cantando victoria, aunque tembleque de piernas y con un algo demacrado el semblante. -Le quité el rigio por lo menos para un mes -les había dicho desde la acera, enseñándoles el cheque del Banco Hipotecario firmado por La Bella Cupida. (48-49)

De esta forma cada segmento temporal que va dibujando los contornos del grupo de conspiradores resulta en la desmitificación de los héroes. Tal es el caso de Cornelio Selva. Este personaje tenía una larga historia de actividades subversivas y era quien los servicios de inteligencia esperaban atentara contra Somoza; sin embargo, el gran enemigo de la dictadura no sólo es arrestado sino que no tiene ninguna posibilidad de matar a Somoza.

Lo mismo sucede con las rupturas con las que se introducen los sucesos de la vida de Rubén Darío, también están contagiadas de un 
tono desmitificador que busca restituir al personaje histórico sus dimensiones humanas.

La investigación de Rigoberto entrelazada con la voz del narrador presenta diferentes momentos de los últimos años de Rubén Darío: 27 de octubre y 18 de noviembre de 1907; 7 y 8 de abril de 1908; 7 de enero y 6 de febrero de 1916.

Por tanto, dejo que el rostro de la Primera Dama, maquillado sin piedad y avejentado con menos piedad, se mire por su cuenta en el veloz espejo de las aguas del tiempo; que el caer invisible de una piedra agite en ondas la transparente superficie para que ella recobre en el fondo la imagen en temblor de la niña de diez años, vestida de organdí igual que su hermana Margarita, sus sombreros de paja italiana con dos cintas bajando a sus espaldas; que se vea sentada en la barca mecida por el oleaje, donde una parte de ustedes debe apresurarse en buscar lugar.

Es la mañana del 27 de octubre de 1907 y de lejos se avizora ya el Pacific Mail, a cuya cubierta otros de ustedes harían bien en subir, pues allí llega aquel que yace bajo el león de cemento, en su retorno a la tierra natal... (17-18)

Como se puede observar, el primer párrafo corresponde a una analepsis introducida por el narrador principal y el segundo a la vida de Rubén Darío que reconstruye Rigoberto. La escritura de este relato pone de manifiesto el interés del investigador por incorporar en su discurso los niveles vivenciales de la historia y así dotar de una dimensión real al personaje histórico. De ahí que utilice estrategias literarias que se enfrentan con la idea de "verdad" que presupone el discurso histórico:

Rubén se hunde en las almohadas, y con los ojos cerrados escucha el golpe sordo y apresurado de los tacones bajando la escalera. Se incorpora a medias. Sobre las sábanas revueltas descubre la diadema con el airón de plumas. -Disfraces de carnaval -piensa, y tira la diadema al piso. -Ya llegamos a un punto en que Rigoberto sabe hasta lo que Darío estaba pensando -dice Erwin. (100-101) 
En el pasaje anterior queda de manifiesto la conceptualización de la historia como una disciplina que implica objetividad, que al lindar con los terrenos de lo ficcional -la representación del pensamiento del personaje histórico- pierde su carácter real. Sin embargo y a pesar de que los narratarios continuamente discuten el valor de verdad de la historia de Rigoberto, reconocen el valor de la investigación, al grado que consideran cierto el relato que les hace éste:

El viento arrecia en el jardín en sombras y voltea las dos mecedoras vacías. Huyen los pavorreales. Retumba un trueno poderoso y los argentados chorros de lluvia empiezan a caer en torrente bullicioso desde los aleros con un sonido alegre de voces de mujeres.

-¿Quién estaba allí filmando esa película? -dice Erwin mientras Rigoberto cierra el cuaderno.

-Son reconstrucciones históricas - dice el Capitán Prío-. No hay que dudar de ellas. (69)

El narrador presenta, también por medio de analepsis y prolepsis, diferentes momentos de la vida de los personajes: Quirino y la Caimana, Anastasio Somoza o Cordelio Selva por mencionar algunos de la amplia galería de personajes de la novela. Por ejemplo, en el siguiente pasaje refiere el pasado y el futuro de la Caimana:

Seis meses habían pasado presos en los calabozos de Santos Lugares el pirotécnico Apolonio Aguire, alias El Dragón Colosal, y su niña de siete años, Filomela Aguirre a quien la fama conocerá más tarde como la Caimana por esos sus dientecitos filosos, capturados por órdenes del general Silvano Quirino, ElPresidente Chiquito, cuando cortaban en sus dominios carrizos y varillas para fabricar cohetes. (186)

La voz narrativa principal reconoce a Rigoberto como la voz que lo auxilia para reconstruir los pasajes relativos a la vida de Rubén Darío. El autor implícito hace de Rigoberto un narrador para vincularlo personalmente con el poeta nicaragüense y así legitimar una 
genealogía intelectual prestigiosa para el que más tarde será el asesino del dictador:

Pero hay más sobre este aposento. Así que mientras el Capitán Prío no descuida a La Caimana, permítanme que yo haga volar las hojas del calendario en raudo torbellino; dispongo de un auxilio eficaz para este efecto (que ustedes luego podrán conocer) de manera que no nos retrasemos en llegar a la noche del 7 de abril de 1908, muy próxima ya la partida de Rubén, de regreso a Europa.

Ahora pueden verlo de muy cerca. Escribe algo en el espejo detrás del candelabro. La huella de un golpe que hincha su pómulo le enciende el ojo con un fulgor de rubí que se refleja en el espejo. (93)

La palabra es el hilo que utiliza Sergio Ramírez para unir estos dos tiempos, pues por medio de ella va tejiendo una voz, una instancia de enunciación que, aunque como decía, contagiada del tono modernista, se constituye en la mediadora entre los sucesos narrados y el lector, de manera que da lugar a la presentación de múltiples voces y diversos registros discursivos.

El tejido textual se sostiene en un conjunto de voces que atienden a la presentación de los sucesos, no desde la grandilocuencia de la historia, sino desde un discurso que da cuenta del contexto cotidiano de la intimidad.

Por medio de esta multiplicidad de voces y registros se presentan los sucesos novelescos, en donde las formas de representación de los personajes históricos - desde un Rubén Darío dipsómano y en decadencia, pasando por un tirano sin ano, hasta un tiranicida con mala puntería- se pudieran entender como una parodia del discurso de la historia. Sin embargo, más que parodiar la historia, la novela ofrece una conceptualización que debate con los esquemas ideológicos de la historia misma, al reducir al personaje histórico a sus dimensiones humanas, íntimas y cotidianas, en la que se hacen evidentes sus contradicciones internas, debilidades y veleidades. 
Sin duda, el elemento cohesionador de la novela es la constitución de una voz narrativa, cuyo tono y funcionamiento corresponde al de un narrador decimonónico que a la vez funciona como un narrador contemporáneo pues, aunque continuamente interpela al lector y a los mismos personajes, también actúa junto con la voz de un personaje narrador que presenta sus propias indagaciones y puntos de vista y, al mismo tiempo, incorpora al mundo novelesco diversos registros discursivos como el diálogo teatral, el discurso legal, el de la investigación histórica o el del reportaje.

Si el tiempo se une con el hilo de la palabra, el espacio se une por medio de los personajes que lo habitan. Dos personajes, Quirón y la Caimana, habitan ese espacio en los dos diferentes momentos y son ellos los hilos que le dan unidad. El primero recibe el numen de Rubén de Darío y la segunda es la artífice de la boda entre Anastasio Somoza y Salvadorita Debayle. Ambos personajes, con orígenes oscuros, contradiciendo así el discurso de la historia, son los que determinan el devenir histórico. El príncipe de los Cisnes, Rubén Darío, hace de Quirón el heredero de su poesía; Quirón es el maestro de Rigoberto López Pérez quien da muerte a Somoza. Anastasio Somoza logra contraer matrimonio con Salvadorita, toda vez que le ofrece al Sabio Debayle la oportunidad de realizar una operación de cambio de sexo a la Caimana, que es a su vez quien recibe en empeño el arma del tiranicida. El intrincado tejido de los personajes que se zurce a partir de sus debilidades y temores.

La novela contiene, entonces, un mosaico de personajes ubicados en diferentes estratos sociales que al interrelacionarse llegan a incidir en el devenir histórico. Pero su actuación no está sustentada en una voluntad explícita. Todo parece ser producto del azar y, en este sentido, podemos descifrar una actitud de desencanto ante la historia en Sergio Ramírez. Como señala Mark Bates:

Somoza García is painted as a swindling, unimaginative criminal worthy of neither esteem nor contempt. This becomes the ultimate criticism of the novel. In a world where true heroism is scorned, epitomized in Rigoberto's patriotic act, and deceit and lies are rewarded, as is the case of Somoza and his cohorts, 
justice and freedom are impossible to achieve and real national heroes can not exist. (50)

Casi nada es resultado de la voluntad de los personajes sino del destino que va hilando las acciones hasta lograr un intrincado tejido en el que todos los personajes, sin proponérselo, terminan por ser actores de la historia. Tal es el caso de Quirino, uno de los personajes que une los dos tiempos; casualmente Darío siente simpatía por él, casualmente estaba en el cementerio y vio cuando los marines hicieron una orgía, escribió un artículo denunciando el hecho por lo que recibió una paliza que lo dejó mudo y, casualmente, estaba en el momento en el que los deudos y el sabio Debayle discutían por la posesión del cerebro de Rubén Darío y decide robarlo y llevarlo al prostíbulo para velarlo. También casualmente puede robar los testículos cortados al cuerpo de Rigoberto.

Como contrapunto de figuración del azar y el destino, Sergio Ramírez construye la imagen del héroe. Todo lo planeado para el atentado se viene abajo; no es que haya traidores, incluso el León de Nemea que era un agente infiltrado, no tiene capacidad para traicionar, simplemente el destino se encarga de tejer los hilos de manera que nada resulte como se planeó. Sin embargo, la voluntad de Rigoberto es tal que actúa aun en contra de sí mismo, porque como dice Hortencia Campanella, Rigoberto "se irá convirtiendo en el héroe central que lúcidamente se enfrentará a la muerte para cumplir con lo que considera un deber patriótico: matar al dictador". Entonces, la capacidad de decisión de Rigoberto se convierte en contrapunto del destino. El problema es que aun esta capacidad queda sujeta a la fatalidad, porque aunque practicó tiro al blanco, a la hora del atentado falla y si muere Somoza es más bien por resultado del azar, porque no murió en el momento en que Rigoberto le disparó a quemarropa.

La propia historia de Somoza, relatada en el curriculum vitae escrito por Rigoberto y presentado en el "Intermezzo tropical", parece ser resultado de la suerte, pues de inspector de letrinas llega a ser dictador de Nicaragua. No es que Somoza se hubiera propuesto serlo sino que las cosas se le dieron de tal modo que alcanzó el poder. 
La tematización del destino como un factor determinante para el devenir histórico se puede reconocer en las historias paralelas de Quirino y la Caimana. Ambos personajes nacen el mismo día en condiciones adversas, el primero nace "en la caseta de un excusado", y es producto de los amores del Santo Mardoqueo, un cura del pueblo, y de la planchadora de la catedral, la Tigresa de Bengala. La Caimana nace en medio de un incendio en el que muere su madre, $\mathrm{y}$ sus primeros años los pasa con su padre, un hombre de oficio cohetero, quien se ve obligado a dejarla en el hospicio del Santo Mardoqueo donde la violan siendo una niña:

-Y eso del nacimiento a la misma hora, y el cielo encendido con los juegos pirotécnicos ya es ópera-dijo Erwin.

-Así se cruzan los destinos, en medio de berridos y grandes algarazas -dijo Norberto.

-El destino de un mudo lunático y de una rufiana -dijo Erwin - ¿No le llevó Quirón el cerebro de Rubén a La Caimana después de robárselo? - dijo Roberto-. Allí tienen un nuevo cruce de sus destinos.

-Antes, el destino los juntó en el cementerio, luego van a oír esa parte-dijo Norberto. (202)

Así, la Caimana es la contraparte de Quirino, es el personaje que encarna la fuerza animal capaz de sobrevivir en las peores circunstancias, a la que el destino condujo por caminos sombríos, aunque su padre trató de llevarla ante Rubén Darío para pedirle que empleara a su hija "para alimentar a sus cisnes". Mientras que Quirino, por azar se convirtió en discípulo de Rubén Darío, quien le abrió los caminos de la inteligencia y la sensibilidad.

Con esta pareja de personajes contrapuestos, Ramírez termina de dar cuerpo a la conceptualización de la historia como un tejido azaroso en el que la voluntad humana se enreda y no logra siquiera alcanzar a dibujarse metas distintas a las que el azar la lleva, de manera que sólo una voluntad heroica puede intentar contravenir el destino y modificar el devenir de la historia. En la novela, entonces, se combinan los tiempos históricos y se ficcionaliza el actuar de los 
personajes para restituir al discurso de la historia la dimensión humana y cotidana.

\section{Bibliografía}

Bates, Mark. "Interweaving Narrative Discourse in Sergio Ramírez's Margarita, está linda la mar". Céfiro 1-2. (2005): 44-50.

Campanella, Hortencia. "El destino prodigioso y fatal". <http:// www.sergioramirez.org.ni/campanella.html>.

Menton, Seymour. "Margarita, está linda la mar, una Nueva Novela Histórica en la época posrevolucionaria: 1989-2000”. Istmo: Revista virtual de estudios literarios y culturales centroamericanos. No. 3 enero-junio 2002. <http://istmo.denison.edu/n03/articulos/ margar.html>.

Ramírez, Sergio. Margarita, está linda la mar. Madrid: Alfaguara, 1998. Rodríguez Rosales, Isolda. Una década de narrativa nicaragüense y otros ensayos. Managua: Centro Nicaragüense de escritores, 1999.

Chatman, Seymour. Historia y discurso. Madrid: Taurus, 1990. 